\title{
Leaders
}

\section{Problematic pigmented lesions: approach to diagnosis}

\author{
S L Edwards, K Blessing
}

\begin{abstract}
A number of pigmented lesions are difficult to classify and raise the possibility of a melanoma diagnosis. Care should be exercised to exclude non-melanocytic lesions, and benign melanocytic entities, both of which can mimic melanoma histologically. In addition, the possibility of the lesion being a melanoma variant or epidermotropic metastasis should be considered. There will still be some cases that are difficult to resolve. These usually fall into one of three categories: atypical junctional melanocytic lesion versus early melanoma; naevus versus naevoid melanoma; and atypical Spitz, cellular blue, and deep penetrating naevi versus thick melanoma. These will pose problems even for experts. The atypical Spitz lesions are perhaps the most important category because they tend to be from younger individuals, the differential diagnosis is thick melanoma, and there is no single discriminating histological feature. (F Clin Pathol 2000;53:409-418)
\end{abstract}

Keywords: difficult diagnosis; pigmented lesions; melanoma

Pigmented skin lesions comprise a large component of most histopathologists' workload, and although there is a wide spectrum of histological appearances, most can be reported as simple benign naevi. A small number will be typical malignant melanomas. However, some pigmented skin lesions will be more difficult to classify when there are unusual features present such as asymmetry of the silhouette, excessive junctional activity, deep extension into the subcutis, cellular pleomorphism, or mitotic activity. These latter cases, although small in number, are very important clinically because of the time and attention they require and the potential for litigation, as a result of both under and over diagnosis of melanoma. ${ }^{1}$ Therefore, it is important to approach all melanocytic and pigmented lesions in a ritualistic and consistent manner to avoid potential serious diagnostic errors. Our review attempts to present a logical approach to this problem and highlights the problematic diagnostic areas, particularly Spitz naevi.

\section{General guidelines}

Before looking at a pigmented lesion it is vital to know certain clinical factors, particularly the age of the patient, the anatomical location of the lesion, and if there has been previous surgery or trauma. The age is important because melanomas are more common with increasing age and are extremely rare (although they do occur) in children. ${ }^{2}$ Spitz naevi occur predominantly in children and young adults, and are increasingly uncommon in the older age groups. ${ }^{3}$ Some features related to an actively growing lesion are more acceptable in children and adolescents than they would be in an adult. For example, a lentiginous junctional growth pattern in an adult would be a pointer to in situ melanoma, whereas it would not infer the same in a child.

It is also essential to know the site of the biopsy. This is important for two reasons. First, different anatomical locations have different qualities of skin, which cause both benign and malignant melanocytic lesions to grow in characteristic patterns. This is particularly pertinent to the in situ component of melanomas, which aids their recognition. For example, lentigo maligna occurs on sun exposed skin of older individuals and presents as a lentiginous proliferation of atypical melanocytes in an atrophic epidermis. Benign melanocytic lesions at these sites and in this age group are predominantly intradermal naevi. ${ }^{4}$ Acral lentiginous melanoma in situ occurs on acral skin and histologically grows as a subtle lentiginous proliferation on the background of an epidermis with psoriasiform hyperplasia, whereas acral naevi are typically nested and can show florid junctional activity (figs 1 and 2). Second,

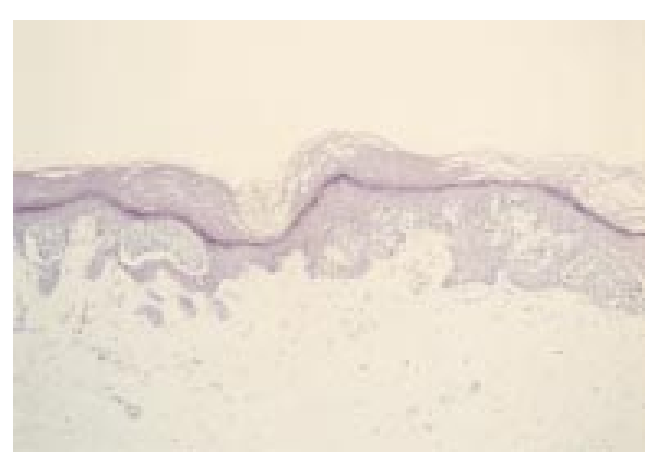

Figure 1 Acral naevus. At low power there is pronounced junctional activity. No psoriasiform hyperplasia is seen. 
Table 1 Non-melanocytic entities that can mimic melanocytic lesions

Atypical fibroxanthoma Bednar tumour Clear cell dermatofibroma Epithelioid histiocytoma

Extramammary Paget's disease

Granular cell tumour

Mastocytoma

Metastatic lobular carcinoma

Mycosis fungoides

Neurothekeoma

\section{Table 2 Benign}

melanocytic entities that

can mimic thick melanoma

Ancient naevus

Balloon cell naevus

Cellular blue naevus

Combined naevus

Compound Spitz naevus

Deep penetrating naevus

Desmoplastic naevus

Naevus with dermal nodules

Table 3 Benign

melanocytic entities that

can mimic thin melanoma

Acral naevus

Genital naevus

Halo naevus

Junctional/pagetoid Spitz naevus

Naevus of infancy

Naevus from special anatomical sites

Naevus after UV irradiation

Pigmented spindle cell naevus

Pseudomelanoma

Table 4 Malignant melanoma variants that can mimic benign lesions

Balloon cell melanoma Desmoplastic melanoma Regressed melanoma Small (non-Merkel) cell melanoma

Spitzoid melanoma

Varicose melanoma

Verrucous naevoid melanoma

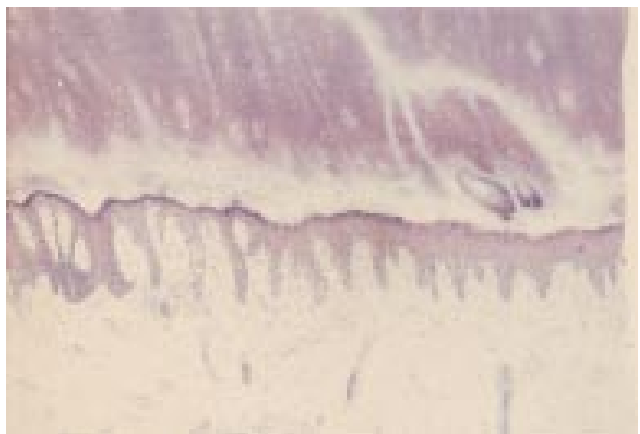

Figure 2 Acral lentiginous melanoma in situ. At low power there is psoriasiform hyperplasia of the epidermis with a subtle lentiginous proliferation of melanocytes along the basal layer.

benign melanocytic lesions from certain sites in the body can, as a normal feature, exhibit architectural and possibly cytological atypia (see below). Therefore, care should be exercised when examining naevi from these sites to prevent over diagnosing atypical naevi or melanoma.

It is also important to know whether there has been a previous shave biopsy or incomplete excision, because regrowth of melanocytes in scar tissue can mimic melanoma, and create a so called pseudomelanoma phenomenon. ${ }^{5}$

For the remaining lesions that are not readily classifiable, all the tissue should be examined, with levels cut where appropriate. Before agonising and spending time on these cases it is important first to exclude lesions that can mimic melanoma and to consider melanocytic lesions that are recognised entities, and which could account for the atypical features present within a particular melanocytic lesion. These other lesions to be considered and excluded can be categorised as follows:

- Non-melanocytic entities that might be clinically pigmented and histologically can mimic melanocytic lesions (table 1).

- Benign melanocytic entities that can mimic malignant melanoma:

(1) Those that mimic thick melanoma (table 2).

(2) Those that mimic thin melanoma (table 3).

- Malignant melanoma variants that can mimic benign melanocytic lesions (table 4).

- Epidermotropic metastatic melanoma that can mimic primary melanoma and benign naevi.

\section{Non-melanocytic lesions that can mimic melanocytic lesions}

These lesions can mostly be excluded if a thorough examination is undertaken and appropriate special stains are performed. Melan-A and S100 stains are the most useful to detect melanocytic lineage, with S100 being more sensitive but less specific than Melan-A. Both stain benign and malignant melanoctyic cells strongly and diffusely, with the exception of Melan-A in desmoplastic melanomas, where there is little or no staining. ${ }^{67}$ All of the lesions in this group are Melan-A negative. ${ }^{7}$ Most are S100 protein negative, with only granular cell tumours being S100 protein positive, and most but not all reports of cellular neurothekeoma being S100 negative. ${ }^{7}$

\section{ATYPICAL FIBROXANTHOMA}

This tumour occurs most commonly on sun exposed skin of elderly individuals, and is composed of atypical histiocyte like cells, giant cells, and spindle cells. Mitotic figures including atypical forms are usually readily identifiable. It is a diagnosis of exclusion with S100 protein, Melan-A, and pancytokeratin staining being negative. ${ }^{89}$ More recently, a monomorphic spindle cell variant and a pigmented variant have been described, which have the clinical and immunohistochemical pattern identical to typical atypical fibroxanthoma. The former variant lacks the prominent cellular pleomorphism, being composed predominantly of spindle cells, ${ }^{10}$ whereas the cellular component of the pigmented variant contains erythrocytes and/or haemosiderin in the cytoplasm. ${ }^{11}$

BEDNAR TUMOUR

Pigmented dermatofibrosarcoma protuberans although rare could mimic spindle cell melanoma. ${ }^{12}$

\section{CLEAR CELL DERMATOFIBROMA}

This is a rare variant of dermatofibroma, which tends to occur on the lower limbs of middle aged adults. Microscopically, it is a well circumscribed dermal to subcutaneous tumour, which stains faintly, because over $90 \%$ of the constituent cells have a clear cytoplasm and stain with PAS (periodic acid Schiff). They may mimic balloon cell naevus and/or melanoma, but they are $\mathrm{S} 100$ protein and cytokeratin negative. ${ }^{13}$

\section{EPITHELIOID HISTIOCYTOMA}

This is an unusual and still poorly recognised variant of dermatofibroma that was first described by Edward Wilson-Jones et al in 1989 , and typically presents as a nodule on the extremities. ${ }^{14}$ It differs from conventional dermatofibroma in its relatively sharp circumscription, prominent vascularity, centering on the papillary dermis, predominance of epithelioid cells, and relative lack of other secondary features such as haemosiderin and giant cells $^{14}{ }^{15}$ (figs 3 and 4). A deep seated cellular variant has been recognised. ${ }^{16-19}$ This entity can mimic other non-fibrohistiocytic tumours such

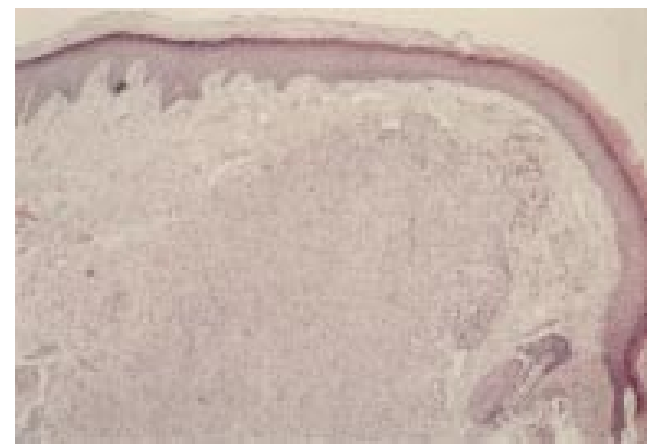

Figure 3 Epithelioid cell histiocytoma. A cellular dermal nodule with a Grenz zone. The lesion extends into deeper tissues. 
as desmoplastic Spitz naevus and pyogenic granuloma. In some cases, the differential diagnosis of secondary melanoma might be considered because of the presence of a rare mitotic figure and the lack of maturation in its depth (fig 4). The epithelioid cell histiocytoma can be distinguished by its symmetry, circumscription, absence of a true junctional component, nesting, and melanin pigmentation, and can be confirmed by the immunohistochemical profile.

EXTRAMAMMARY PAGETS DISEASE, GRANULAR CELL TUMOUR, MASTOCYTOMA (FIGS 5-7), METASTATIC LOBULAR CARCINOMA, AND MYCOSIS FUNGOIDES

In certain instances, these entities can be mistaken for both benign and malignant melanocytic lesions. All are Melan-A negative, and all with the exception of granular cell tumour are $\mathrm{S} 100$ protein negative.

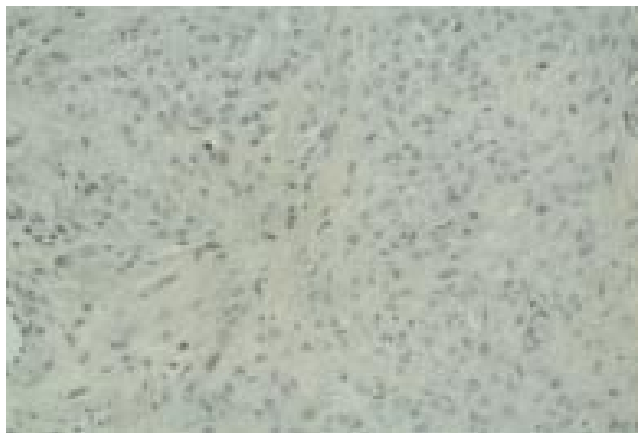

Figure 4 Epithelioid cell histiocytoma. Cells are epithelioid and there is no apparent maturation. A mitotic figure is present. A recent case at the Scottish melanoma group (with permission from Dr KM McLaren, Edinburgh). The differential diagnosis is atypical Spitz, atypical cellular blue naevus, and metastatic melanoma. The lesion was $S 100$ protein negative.

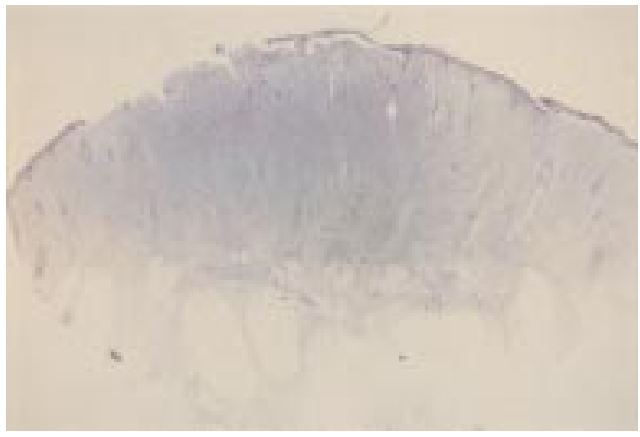

Figure 5 Mastocytoma. A cellular dermal lesion with overlying ulceration and extension of the cells into the fat.



Figure 6 Mastocytoma. Constituent cells of fig 5. The cells have a moderate eosinophilic cytoplasm. There is mild to moderate nuclear atypia.

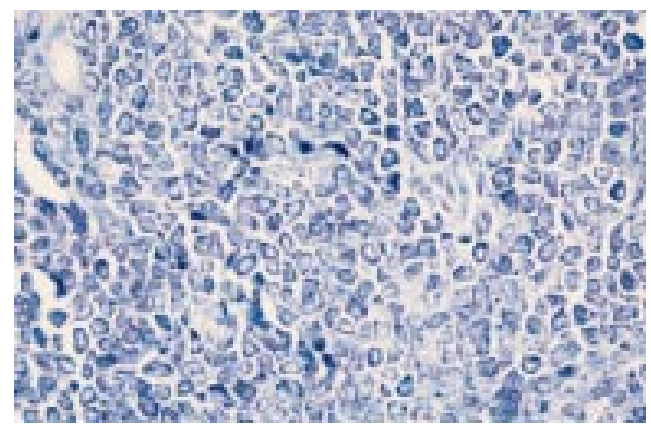

Figure 7 Mastocytoma. Toluidine blue staining of cells. Cells were $S 100$ protein and Melan-A negative.

NEUROTHEKEOMA

There is considerable confusion as to the terminology and the histogenesis of these lesions. Similar appearing lesions have been called nerve sheath myxomas, pacinian neurofibromas, and neurothekeoma. ${ }^{20-23}$ They have been subdivided into cellular and myxoid variants with different clinical, histological, and immunohistochemical appearances. ${ }^{24}$ The myxoid variant, occurring in older individuals, is a well circumscribed encapsulated tumour located in the reticular dermis, and is composed of packets of myxoid stroma containing whorls or fascicles of spindle cells. The cells are bipolar in appearance. The tumour cells are S100 protein positive, and negative for myelin basic protein (MBP), epithelial membrane antigen (EMA), and glial fibrilliary acid protein (GFAP). The cellular variant occurs in individuals of a wide age range. ${ }^{24-26}$ It is described as being limited to the reticular epidermis with a Grenz zone. The tumour is multilobular and composed of plump spindle cells or epithelioid cells arranged in a concentric or linear array. There might be nuclear pleomorphism and hyperchromasia. Occasional mitotic figures have been described. There is confusion regarding the immunohistochemical profile, with most studies claiming that the cellular variant stains S100 negative , ${ }^{24}$ whereas one group claims that the staining pattern is positive. $^{27}$

Clearly, this is a heterogeneous group of lesions but the importance is to consider these in relation to desmoplastic melanoma. When encountering a spindle cell lesion with atypia and mitotic activity from the head and neck area in an older individual, which stains S100 positive, it would be prudent to consider it more likely to be a desmoplastic melanoma than a neurothekeoma. Careful attention should be made to the dermo-epidermal junction, although a junctional component is not always required for the diagnosis of desmoplastic melanoma (see below).

\section{Benign melanocytic lesions that can mimic melanoma}

THOSE THAT CAN MIMIC THICK LESIONS

Ancient naevus

Some naevi from the face of older ( $>50$ years) individuals can show some degree of atypia that could lead to the erroneous diagnosis of melanoma, particularly melanoma arising in association with benign naevus. These lesions 
are usually exo-endophytic, intradermal proliferations composed of two populations of cells. One population has large pleomorphic nuclei and might resemble Spitz cells, and the other is a population of small monomorphous cells. There might be secondary degenerative changes, which include thrombi, zones of haemorrhage, pseudoangiomatous pattern, thick rims of sclerosis around dilated venules, and mucin. A few mitotic figures might be present. ${ }^{28}$ However, if the mitotic figures are in the base of the lesion, are atypical, or numerous, the diagnosis is almost certainly that of melanoma. ${ }^{29}$

\section{Balloon cell naevus}

These have the conventional histology of naevi with variable amounts of balloon cells as constituent cells. The balloon cells are large, round to oval, and have abundant clear or pale foamy cytoplasm. They need to be differentiated from balloon cell melanoma. ${ }^{30}$

\section{Cellular blue naevus}

Blue naevi have traditionally been divided into common and cellular blue types but the separation is artificial because there is frequent overlap. Lesions, which are predominantly cellular blue naevi, can mimic both primary and secondary melanoma. They can cause diagnostic difficulty if they are of a large size, and extend into fat. They are typically unencapsulated and grow in fascicles or in an alveolar pattern. They can show mild cytological atypia. ${ }^{31}{ }^{32}$ Myxoid change has been described as a degenerative phenomenon in large lesions and this is associated with cellular pleomorphism and pseudovascular invasion. ${ }^{33}$ However, these myxoid areas are in the centre of the tumour, and myxoid areas are not a feature of lesions that have been called malignant blue naevus. Epithelioid and sclerosing variants of blue naevus have also been described, ${ }^{34}{ }^{35}$ as have atypical cellular blue naevi, which exhibit cytological atypia but have a benign clinical behaviour. ${ }^{36}$ Features indicating malignancy in blue naevi like lesions are pronounced cytological atypia, gross variation in pigmentation, foci of necrosis, and numerous mitotic figures. ${ }^{37}$

\section{Combined naevus}

Any combination of naevi can occur within the same lesion-for example, Spitz, blue, and common naevi, and this can cause diagnostic problems, particularly if there is a deep component. ${ }^{38}$

\section{Compound Spitz naevus}

Spitz naevi can be junctional, compound, or intradermal (desmoplastic naevus). They can also be part of a combined naevus. In all these situations they can cause major diagnostic problems, with the differential diagnosis being melanoma. These lesions form a major component of expert referral practices. ${ }^{39}$ It is particularly the deep compound lesions that cause most of the diagnostic problems because they frequently occur in children and young adults, and if diagnosed as melanoma they carry a poor prognosis.
Typically they are non-pigmented, symmetrical, and composed of either large epithelioid and/or spindle cells. There might be pronounced cytological atypia, with nuclear atypia and mitotic figures, and intranuclear inclusions. The cells should have an infiltrative growth pattern at the lower margin, with cells drifting in single fashion between the collagen bundles. The overlying epidermis frequently shows pseudoepitheliomatous hyperplasia, the stroma is oedematous, particularly in the upper portion, and there are Kamino bodies in the papillary dermis. ${ }^{40-43}$ Many authors have emphasised that there is no single discriminating factor for melanoma and compound Spitz naevi, because virtually every attribute of Spitz naevi has been described in melanoma. ${ }^{44-50}$ The most dependable discriminating features are the lack of maturation of the cells at the base, presence of numerous, deep, or atypical mitoses, and deep extension in a bulbous manner into the fat, which favour a diagnosis of melanoma over Spitz naevus. ${ }^{51}$

Spitz lesions that show some of these latter features and yet lack the full criteria for the diagnosis of melanoma have been termed by some "atypical Spitz lesions". Barnhill et al have described these lesions in children and young adults. ${ }^{52}$ In general, they are larger than Spitz naevi, are asymmetric with deep extension (mean depth, $4.36 \mathrm{~mm}$ ), show prominent cellularity, and have deeply located mitoses, occasional atypical mitoses, and cytological atypia, with some having dermal nodules with rounded pushing margins. These features are similar to those described by Smith et al, also in young adults, ${ }^{50}$ and he called these lesions malignant Spitz naevi. In Smith's series, six of the 32 cases had resulted in nodal metastasis, but they could not distinguish histologically those lesions that did not metastasise from those that did. This is similar to Barnhill's series, where histology could not separate those lesions that he called "atypical Spitz tumours" from those that he categorised as "metastasising Spitz naevi". ${ }^{52}$

The problem is further confounded by the proposal that there exists a group of Spitz tumours in children that will result in nodal metastasis, but will not progress beyond this stage. These have been called "malignant Spitz naevi" and also "atypical Spitz naevus with metastasis". ${ }^{50} 53$ The problem is the length of follow up. Many, however, would regard these lesions as spitzoid melanomas.

Deep penetrating naevus (plexiform spindle cell naevus)

This was first described by Seab et al in 1989 as a lesion that clinically and histologically can mimic thick melanoma, and occurs predominantly in the head and neck and upper extremities of young individuals. Histologically, they described a symmetrical, wedge shaped lesion, which extended into and had its apex in the reticular dermis or fat (fig 8). The cells are arranged in nests or fascicles interspersed with melanophages (fig 9). The nests surround hair follicles, sweat glands, blood vessels, and nerves. The cells are spindle in 


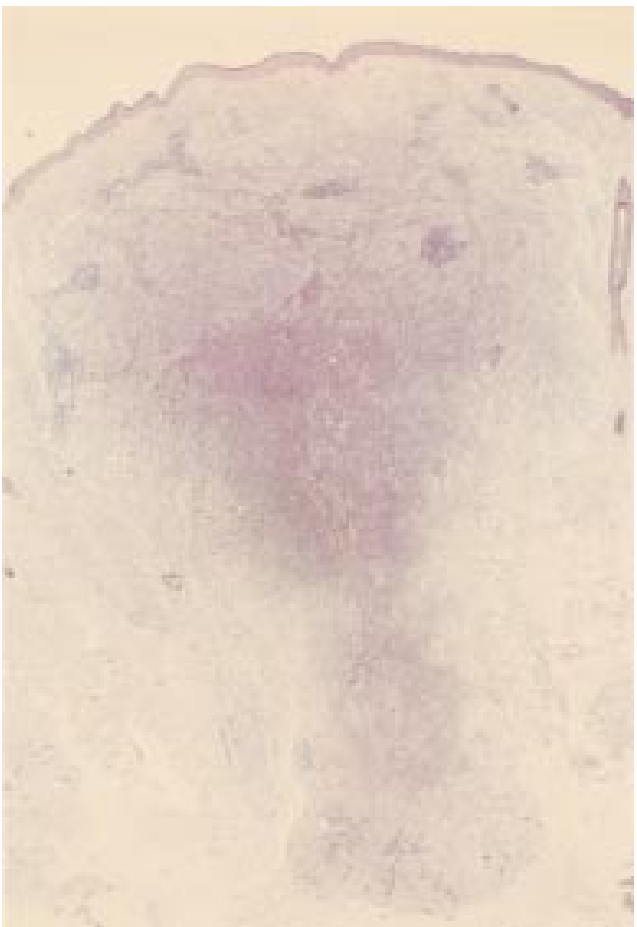

Figure 8 Deep penetrating naevus. Symmetrical dermal lesion extending deeply into the fat. A case from the melanoma slide club (with permission from Dr H Rigby, Bristol). The differential diagnosis is atypical blue naevus and melanoma.

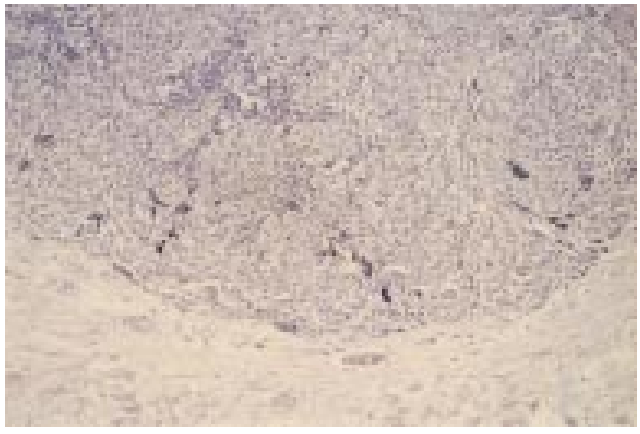

Figure 9 Deep penetrating naevus. The base of the lesion, which is rounded. The cells are growing in a fascicular pattern and there are mild cytological abnormalities. Deep or excessive mitotic activity would raise concerns about the lesion being a melanoma.

morphology, with nuclear pleomorphism, but mitoses are rare. A junctional component is present in most cases..$^{53-57}$ Others have termed similar lesions "plexiform spindle cell naevi", because of their plexiform architecture, and commented that not all lesions were deeply penetrating. ${ }^{58}$ Some of these lesions might be variants of cellular blue naevi. However, the most important differential diagnosis is that of thick melanoma. Seab et al cite the following features as favouring a benign diagnosis: symmetry, inconspicuous junctional component, few mitotic figures, bland chromatin, no reactive stroma, and little inflammation.

Desmoplastic naevus (desmoplastic Spitz naevus, dermatofibroma like Spitz naevus)

This encompasses a lesion that many believe is a variant of Spitz naevus. It can occur at any age, and there is a female predominance.
Histologically, at scanning power, there is an intradermal cellular lesion, which resembles dermatofibroma, but the epidermis is not usually hyperplastic. There is no junctional activity. The cells are epithelioid in type and usually lie singly in a dense eosinophilic collagenous stroma. They can show cytological atypia but mitoses are rare. They might contain giant cells, ganglion type cells, and intranuclear inclusions. Melanin pigment and an inflammatory infiltrate are uncommon. ${ }^{59}$ Although they might mimic dermatofibroma the most important differential diagnosis is that of desmoplastic melanoma. ${ }^{35}$

\section{Naevus with atypical dermal nodules}

These naevi, which present clinically with a new focus of increased pigmentation, have the corresponding histology of sharply demarcated dermal nodules of large melanocytes usually showing mild nuclear atypia. ${ }^{61}$ This entity might be similar to the entities called atypical epithelioid tumours in congenital naevi, proliferating dermal lesions in congenital naevi, bizarre naevi, and naevi with a biphasic dermal pattern. ${ }^{62-66}$ They might be a variant of combined naevus.

However, care must be taken not to diagnose this entity when the diagnosis of a nodule of melanoma developing in a naevus (intralesional transformation) is the appropriate diagnosis. Careful attention to the cytological features, particularly mitoses, of the developing nodule should help to make the distinction.

\section{THOSE THAT CAN MIMIC THIN LESIONS}

This group of lesions comprises predominantly junctional melanocytic proliferations that can mimic early melanoma and atypical (dysplastic) naevi. It includes: junctional/pagetoid Spitz naevus, pigmented spindle cell naevus, acral and genital naevus, naevus following UV irradiation, pseudomelanoma, naevus of infancy, and halo naevus. These lesions have been the subject of a recent review. ${ }^{67}$ Because most of the other lesions can be distinguished with the help of the clinical history, we will discuss junctional Spitz naevus only. Naevi from special anatomical locations other than acral and genital sites will also be mentioned.

\section{Functional Spitz naevus}

Junctional Spitz naevi are the least common variant of Spitz naevi, and the diagnosis should be considered when the melanocytic lesion is predominantly junctional, and is composed of large epithelioid or spindle cells from a child or young adult. ${ }^{51}$ The principal differential diagnosis is early/in situ melanoma. Features favouring the diagnosis of Spitz are young age, the cells all being very similar cytologically to each other, and a uniformity of activity throughout the lesion.

\section{Naevi from special anatomical locations}

It is well recognised that naevi from the acral and genital sites, the latter from premenopausal women, can exhibit architectural and cytological atypia as a normal feature. ${ }^{67}$ However, these atypical features have also been described in 
lesions from certain other sites; namely, axilla, perineum, groin, umbilicus, and inframammary sites. ${ }^{28} 67 \mathrm{a}$ The atypical features seen in these lesions include a lentiginous growth pattern, large nest size, and mild cytological atypia. These factors must be taken into account when assessing melanocytic lesions from these anatomical sites.

\section{Malignant melanoma variants that can mimic benign lesions \\ BALLOON CELL MELANOMA}

These are rare malignant tumours in which the cellular component should contain more than $50 \%$ balloon cells. These cells are large polygonal with abundant vacuolated or finely granular cytoplasm. There is only low grade nuclear atypia and occasional intraepidermal pagetoid spread. ${ }^{68}$ The principal differential diagnosis is that of balloon cell naevus.

\section{DESMOPLASTIC MELANOMA}

Also called neurotropic melanoma, desmoplastic melanomas are a relatively uncommon melanoma variant composed of spindle cells with a prominent desmoplastic reaction and frequent perineural involvement. ${ }^{69-71}$ They occur predominantly, but not exclusively, on the head and neck areas of individuals in their seventh to eighth decade. They are poorly circumscribed, deeply infiltrating (usually $>4 \mathrm{~mm}$ ), and are composed of spindle cells with atypia, no maturation, but with neurotropism, lymphocytic response, mitotic figures, atypical mitotic figures, triangular and periadnexal fibroplasia, and possibly necrosis. Atypical junctional activity is seen in less than half the cases. ${ }^{72}$ They are almost always S100 protein positive and Melan-A and HMB-45 negative $^{67}$ (figs 10 and 11). Although they might be mistaken for a variety of benign and malignant mesenchymal tumours, other important differential diagnoses include desmoplastic naevus, sclerosing blue naevus, and neurothekeoma.

REGRESSED MELANOMA

Malignant melanoma undergoing active regression ${ }^{73}$ can mimic a halo naevus and it is important to differentiate between them. Clinical features can help, in that halo naevi are more common in children and young adults and melanomas are more common in adults,

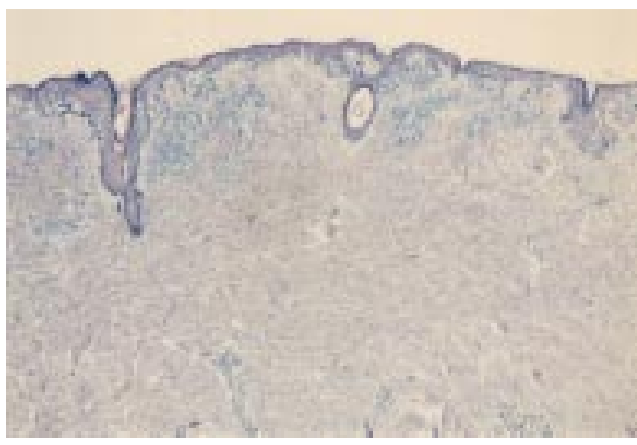

Figure 10 Desmoplastic melanoma. A junctional component is obvious at low power, but the dermis appears to be uninvolved.

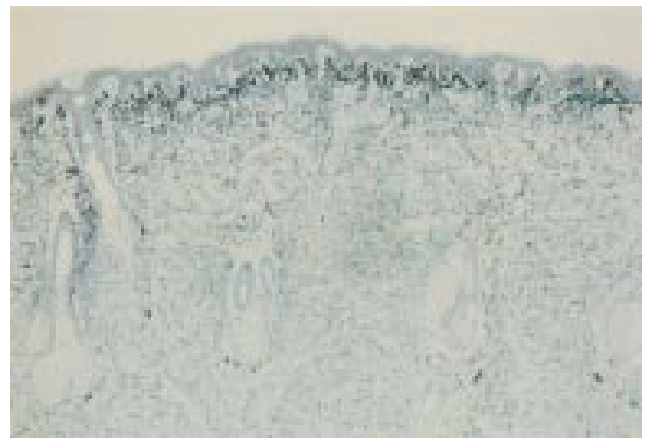

Figure 11 Desmoplastic melanoma. The S100 protein shows the extent of the lesion within the dermis.

although there is potential overlap. Halo naevi tend to be smaller lesions and the regression is equal in intensity and stage throughout the lesion. Patchy variable regressive features in an older individual is a pointer to the fact that the lesion is melanoma. ${ }^{67}$

Melanomas that have undergone complete regression, leaving only heavy dermal melanin pigmentation, can mimic blue naevi. ${ }^{32}$

SMALL CELL (NON-MERKEL) MELANOMA

There are two categories of small cell melanoma. One is Merkel like, and is composed of sheets of small hyperchromatic cells with a high mitotic rate. ${ }^{74}{ }^{75}$ The other is naevus like, and therefore is the one under consideration in this category. This entity is recognised by the presence of an atypical junctional proliferation, which is in situ melanoma, and a dermal component composed of large nests of cells with scanty cytoplasm, nuclear hyperchromasia, and pleomorphism. Between the dermal nests is a prominent vascular response and a patchy lymphocytic infiltrate ${ }^{7676 a}$ (fig 12). They may be misdiagnosed as either benign naevus or in situ melanoma.

\section{SPITZOID MELANOMA}

Most of the features seen in Spitz naevi have been described in melanoma. It is not surprising that a small number of unequivocal melanomas will have several features seen in Spitz naevi, particularly the silhouette and the large epithelioid cells. These have been termed spitzoid melanomas. ${ }^{77}$ These are not Spitz

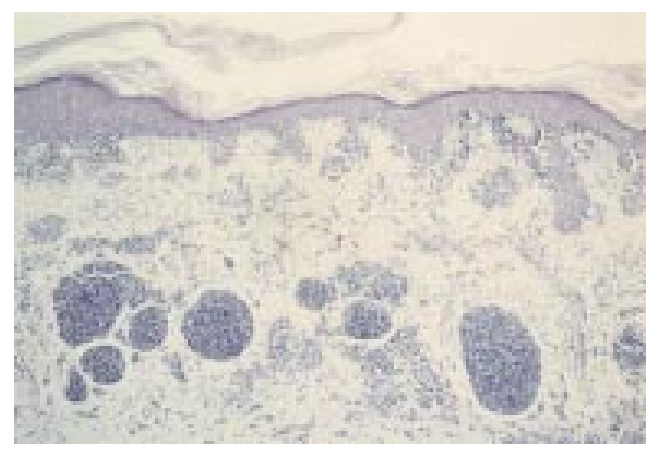

Figure 12 Small cell (non-Merkel) melanoma. There is an atypical junctional component and within the dermis there are nests composed of hyperchromatic cells with scanty cytoplasm and mild cytological atypia. There is a proliferation of small blood vessels between the nests and a patchy lymphocytic infiltrate. The patient was in their sixth decade. 
naevi that have become malignant, but melanomas that resemble Spitz naevi. However, some believe that there is not only a spectrum of histological appearances between Spitz naevi and spitzoid melanoma, but that the two entities represent a biological spectrum of one disease process. ${ }^{79}$

VARICOSE MELANOMA

Malignant melanoma that arises in skin with pronounced stasis damage might be overlooked clinically because of the brownish discoloration of the skin and, histologically, because of the stasis changes in the papillary dermis and the ulcerated and atrophic epidermis. The absence or obscuring of the superficial part of the tumour might lead to the diagnosis of benign naevus when looking at the deeper dermal nests. ${ }^{80}$

VERRUCOUS NAEVOID MELANOMA

This is a heterogeneous group of melanomas, which comprises melanomas with a warty hyperkeratotic appearance, and others that resemble papillomatous benign intradermal naevi at low power, but at high power can be seen to be cytologically malignant. ${ }^{81-87}$ However, a very small proportion will be composed of small naevus like cells, which lack maturation, and have another feature that points to melanoma, namely an atypical junctional component, an asymmetric lateral growth pattern, or foci of regression in an older individual (figs 13-15).

In the past (and even currently), some of these groups might have been called minimal deviation or borderline melanomas, particularly the verrucous, small cell, and spitzoid

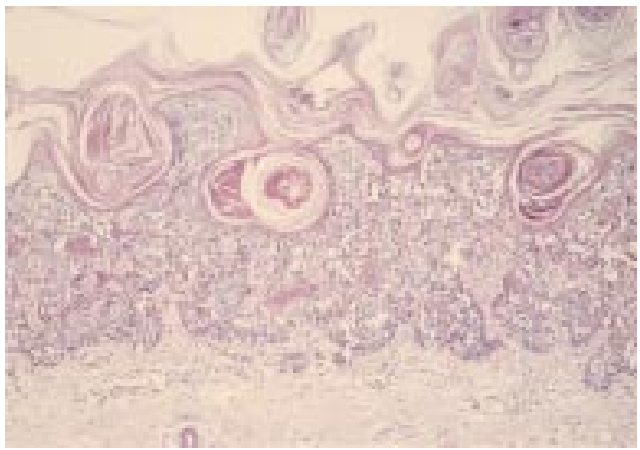

Figure 13 Verrucous small cell melanoma. At scanning power there is a warty looking, rather bland melanocytic lesion, composed of small naevoid like cells.

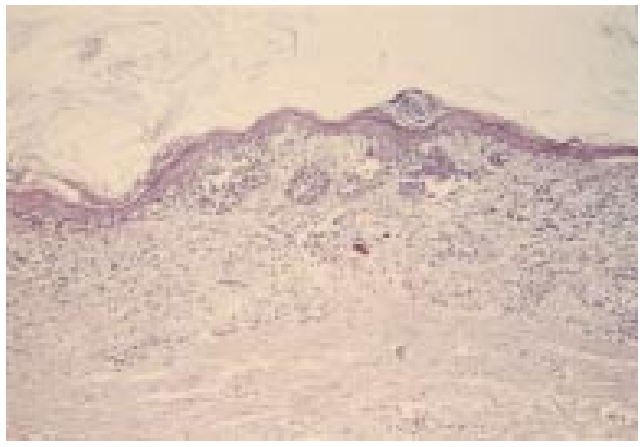

Figure 14 Verrucous small cell melanoma. An area of regression within the lesion.

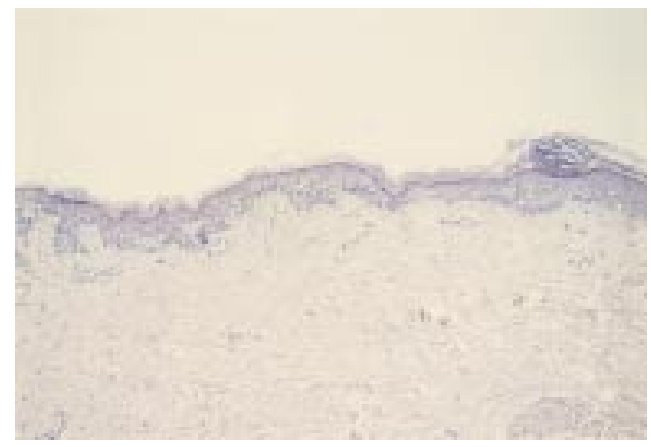

Figure 15 Verrucous small cell melanoma. The lateral growth spread of the lesion. Taken together with the age of the patient, the regression favoured a malignant diagnosis.

types. The terms "minimal deviation melanoma" and "borderline melanoma" have been used to describe melanomas with a less aggressive clinical course and less cytological atypia in their vertical growth component than typical melanomas. ${ }^{6388}$ There is no doubt that not all melanomas behave in a similar clinical manner and some, even though they are in no doubt malignant, behave in a sometimes surprisingly benign fashion. Whether the term minimal deviation is the most appropriate for these lesions remains unresolved. The major problem is that the terminology and defining criteria for minimal deviation lesions appear too vague, with the inclusion of heterogeneous, even possibly benign, melanocytic lesions under this term, making it difficult to compare series and produce prognostic data. The situation has been complicated further by the description of multiple subtypes of minimal deviation melanoma. ${ }^{89}$ Until the problem of terminology is resolved, it is advisable to group together only lesions with very similar histological features to obtain a clearer picture of the clinical behaviour of particular types.

\section{Epidermotrophic metastatic melanoma} that can mimic primary melanoma or naevi

Melanoma that metastasises to the skin (epidermotropic) can mimic, both clinically and histologically, primary melanoma and benign naevus when the clinical information is not available. ${ }^{90} 91$ Melanoma metastases to the skin can also mimic cellular blue naevus. ${ }^{32}$

\section{Atypical melanocytic lesions that are difficult to categorise}

After taking all these factors into consideration, including the clinical history, excluding nonmelanocytic lesions by immunohistochemistry, and melanocytic entities, a small number of problematic melanocytic cases will remain. Although clinical factors can help decide whether a lesion is benign or malignant, they do not help if-for example, the lesion comes from a patient aged between 20 and 30 years, if the lesion looks malignant but the individual is a child, or if there is pronounced atypia in lesions from specific sites, such as acral or genital locations. Most of these lesions would cause diagnostic difficulty even for recognised 
experts in the field of melanoma pathology. The problematic lesions usually fall into one of three groups:

- Atypical, predominantly junctional, naevus versus early melanoma.

- Atypical naevoid lesions versus naevoid melanoma.

- Atypical variants of Spitz/cellular blue/deep penetrating naevi versus thick melanoma.

ATYPICAL PREDOMINANTLY JUNCTIONAL NAEVUS VERSUS EARLY MELANOMA

This is perhaps less of a practical problem, because once excised these lesions should cause the patient no further problems. However, it is important to attempt to achieve the correct diagnosis. The benign melanocytic entities that can resemble early melanoma should be considered and they can cause problems if they show some atypical features. Using pure histology, it might be impossible to separate atypical junctional Spitz and pigmented spindle cell naevi from early melanoma. Some lesions may be called dysplastic naevi, but this term should only be used after following strict adherence to the clinical and histological criteria. ${ }^{67}$

For this group of lesions it is probably important to learn the characteristic appearances of the different types of in situ melanoma and the clinical situations in which they occur. The lesion that one of the authors has described as pigmented lentiginous naevus with atypia, which has also been called lentiginous dysplastic naevus of the elderly, is probably a precursor to an under recognised variant of in situ melanoma (naevoid lentigo maligna), which occurs as large macular lesions, preferentially on the trunk, but also the lower limbs of older individuals. ${ }^{92}$

ATYPICAL NAEVOID LESIONS VERSUS NAEVOID MELANOMA

The group includes naevus like lesions in which the differential diagnosis includes small cell melanoma and the verrucous naevoid group of melanomas. In the former group, features favouring malignancy include an older age, the presence of an in situ melanoma component, dermal nests that are inappropriately large, and reactive stromal features. With the verrucous naevoid lesions, the cytological features usually clearly discriminate between benign and malignant. However, as mentioned earlier, warty melanocytic lesions composed of cells similar to those seen in small cell melanoma and other lesions that look like a papillomatous intradermal naevus but have some other abnormal feature (such as a spreading edge) are more of a problem. Other features have to be considered, including the extent and type of spreading edge, pagetoid invasion, mitotic figures, or areas of regression.

\section{ATYPICAL SPITZ/CELLULAR BLUE/DEEP}

PENETRATING LESIONS VERSUS THICK MELANOMA Although the cases in this group are probably small in number, they are potentially the most important, because they are thick lesions and the prognosis is very different depending on whether the lesion is benign or malignant. The main problem in these atypical variants is how much variation is "acceptable". In the lesions resembling cellular blue or deep penetrating naevi, foci of necrosis and deep or atypical mitotic figures suggest that the lesions should be regarded as melanoma. The most important of this group are the Spitz with atypical features, because of their relative frequency in problematic cases, and because many of them will be from children or young adults. Features causing concern would be deep bulbous extension, lack of maturation, and the presence of multiple, deep, or atypical mitoses. All of these features are completely unacceptable in an adolescent and adult, as is the presence of a pronounced asymmetric junctional melanocytic growth, particularly if lentiginous. The features that are acceptable in a young child are contentious. Barnhill and Smith could not readily separate those spitzoid lesions that metastasised from those that did not on histology alone. ${ }^{50} 52$ Barnhill also suggests that these lesions in children should be divided into high and low risk atypical groups. ${ }^{52}$

\section{Conclusions}

There is a wide spectrum of histological appearances of melanocytic lesions and in interpreting them the clinical and histological features should be considered together. After considering certain non-melanocytic and melanocytic entities, difficulties remain. These difficulties can even be highlighted by the clinical history, when they occur in young adults and children, or where the lesion comes from a special site, such as acral or genital locations.

Consideration should then be given to referring the patient to a recognised expert, but it is acknowledged that there is a spectrum of diagnostic opinion even between experts. ${ }^{147} 93$ One study showed that there was only moderate agreement on a group of melanocytic lesions between recognised experts. These cases had been specifically selected by the experts as lesions that they would have considered for publication to illustrate a typical example of a particular type of melanocytic lesion. ${ }^{47}$ Occasional cases seen in the "British melanoma slide club" and "Scottish melanoma group" also prompt a range of diagnostic opinions.

When the lesion is from a middle aged to elderly adult, the diagnostic problems are less, because the weight of evidence in the background of an atypical melanocytic lesion would favour a malignant diagnosis. The more concerning diagnostic problem is the atypical melanocytic lesions in children and young adults, particularly, the atypical spitzoid lesions. Because of their relative rarity, there are no large series of these childhood lesions with long term follow up to give clearer guidance on diagnostic pointers and prognosis. The few cases that come to light are usually those that have resulted in metastasis, and these are the minority of lesions.

There is as yet no reliable marker to distinguish benign melanocytes from melanoma cells that can be used in every day practice with clear and unambiguous results. Some of the newer proliferation markers might 
be of help. ${ }^{94}$ Even if one is discovered, there would probably still be a grey area, with ambiguous results in those lesions that display more extreme atypical histological features; that is, the cases that cause the problems on histology alone. Until the time that a new antibody or marker is identified, it is important to collect larger series of these lesions with similar histology in an attempt to understand their biological behaviour more accurately. Perhaps the small cell, and some other naevoid melanomas, will have a better prognosis, and certain bizarre histological features might be acceptable as benign in childhood Spitz lesions. Finally, until the problem of the atypical Spitz has been resolved, it might be better to call these lesions "atypical spitzoid lesions of uncertain malignant potential" when found in children and young adults and to suggest follow up.

1 Veenhuizen KCW, De Wit PEJ, Mooi WJ, et al. Quality assessment by expert opinion in melanoma pathology: experience of the pathology panel of the Dutch melanoma working party. F Pathol 1997;182:266-72.

2 Barnhill RL. Childhood melanoma. Semin Diagn Pathol 1998;15:189-94.

3 Weedon D, Little JH. Spindle and epithelioid cell nevi in children and adults. Cancer 197;40:217-25.

4 Blessing K, Husain A, Coburn P. "Benign naevi" in older individuals: diagnostic difficulties [abstract]. F Pathol 1998; 186:35A.

5 Kornberg R, Ackerman AB. Pseudomelanoma. Arch Dermatol 1975;11:1588-90.

6 Blessing K, Sanders DSA, Grant JJH. Comparison of immunohistochemical staining of the novel antibody Melan-A with S100 protein and HMB-45 in malignan melanoma and melanoma variants. Histopathology 1998;32: 139-46.

7 Busam KJ, Chen YT, Old LJ, et al. Expression of Melan-A (MART-1) in benign melanocytic naevi and primary cutaneous malignant melanoma. Am f Surg Pathol 1998;22 976-82.

8 Helwig EB. Atypical fibroxanthoma. Texas fournal of Medicine 1963;59:664-7.

9 Kempson RI, McGavran MH. Atypical fibroxanthomas of the skin. Cancer 1964;76:1463-71.

10 Calonje E, Wadden C, Wilson-Jones E, et al. Spindle cell non-pleomorphic atypical fibroxanthoma: analysis of a series and delineation of a distinctive variant. Histopathology 1993;22:247-54.

11 Diaz-Cascajo C, Borghi S, Bonczkowitz M. Pigmented atypical fibroxanthoma. Histopathology 1998;33:537-41.

12 Bednar B. Storiform neurofibromas of the skin: pigmented and non-pigmented. Cancer 1957;10:368-76.

13 Wambacher-gasser B, Zelger B, Zelger B, et al. Clear cell dermatofibroma. Histopathology 1997;30:64-9.

14 Wilson Jones E, Cerio R, Smith NP. Epithelioid cell histiocytoma: a new entity. Br F Dermatol 1989;120:185-9.

15 Singh-Gomez C, Calonje E, Fletcher CDM. Epithelioid benign fibrous histiocytoma of the skin: clinicopathological analysis of 20 cases of a poorly known variant. Histopathology 1994;24:123-9.

16 Glusac EJ, Barr RJ, Everett MA, et al. Epithelioid cell histiocytoma: report of 10 cases including a new cellular variant. Am 7 Surg Pathol 1994;18:583-90.

17 Glusac EJ, McNiff JM. Epithelioid cell histiocytoma: a simulant of vascular and melanocytic neoplasms. $\mathrm{Am} \mathcal{F}$ Dermatopathol 1999;21:1-7.

18 Botella-Estrada R, Sanmartin O, Perez A, et al. Epithelioid cell histiocytoma: report of 2 cases [abstract]. F Cutan Pathol 1992;19:513(a).

19 Mehregan AH, Mehregan DR, Broecker A. Epithelioid cell histiocytoma. 7 Am Acad Dermatol 1992;26:234-6.

20 Webb JN. The histogenesis of nerve sheath myxoma: report of a case with electron microscopy. F Pathol 1979;127:35-7. 21 MacDonald DM, Wilson-Jones E. Pacinian neurofibroma. Histopathology 1977;1:247-55.

22 Gallager RL, Helwig EB. Neurothekoma-a benign cutaneous tumour of neural origin. Am f Clin Pathol 1980;74 759-64.

23 Fletcher CDM, Chan JKC, McKee PH. Dermal nerve sheath myxoma: a study of three cases. Histopathology 1986;10:135-45

24 Barnhill RL, Dickersin GR, Nickelait V, et al. Studies on the cellular origin of neurothekoma: clinical, light microscopic, immunohistochemical, and ultrastructural observations. $\mathscr{f}$ Am Acad Dermatol 1991;25:80-8.

25 Rosati LA, Fratamico CM, Eusebi V. Cellular neurothekeoma. Appl Pathol 1986;4:186-91.

26 Carlonje E, Wilson-Jones E, Smith NP, et al. Cellular "neurothekeoma": an epithelioid variant of pilar leiosis of a series. Histopathology 1992;20:397-404. 27 Zelgar BG, Steiner H, Kutzner H, et al. Cellular "neurothekeoma": an epithelioid variant
broma? Histopathology 1998;32:414-22.

$28 \mathrm{Kerl} \mathrm{H}$, Soyer HP, Cerroni L, et al. Ancient melanocytic nevus. Semin Diagn Pathol 1998;15:210-15.

29 Smith NP. Histopathological differential diagnosis. In: Kirkham N, Cotton DWK, Lallemand RC, et al, eds. Diagnosis and management of melanoma in clinical practice. London: Springer-Verlag, 1992:75-96.

30 Schrader WA, Helwig EB. Balloon cell naevi. Cancer 1967;20:1502-4.

31 Rodriguez HA, Ackerman LV. Cellular blue nevus. Clinicopathological study of forty five cases. Cancer 1968;21:393405 .

32 Busam KJ. Metastatic melanoma to the skin simulating blue nevus. Am $\mathcal{F}$ Surg Pathol 1999;23:276-82.

33 Michal M, Baumruk L, Skalova A. Myxoid change within cellular blue naevi: a diagnostic pitfall. Histopathology 1992; 20:527-30

34 Carney JA, Ferreiro JA. The epithelioid blue nevus. A multicentric familial tumor with important associations, including cardiac myxoma and psammomatous melanotic schwannoma. Am F Surg Pathol 1996;20:259-72.

35 Chan GSW, Choy C, Ng WK, et al. Desmoplastic melanoma on the buttock of an 18 year old girl: differentiation from desmoplastic naevus. Am f Dermatopathol 1999; 21:170-3.

36 Avidor I, Kessler E. Atypical cellular blue nevus-a benign variant of cellular blue nevus. Presentation of three cases. Dermatologica 1977;154:39-44.

37 Goldenhersh MA, Savin RC, Barnhill RL, et al. Malignant blue nevus. Case report and literature review. $7 \mathrm{Am} \mathrm{Acad}$ Dermatol 1988;19:712-22.

38 Pulitzer DR, Martin PC, Cohen AP, et al. Histologic classification of the combined nevus. Analysis of the variable expression of melanocytic nevi. Am F Surg Pathol 1991;15: 1111-22.

39 Orchard DC, Dowling JP, Kelly JW. Spitz naevi misdiagnosed histologically as melanoma: prevalence and clinical profile. Melanoma Res 1997;7:45s

40 Spitz S. Melanomas of childhood. Am f Pathol 1948;24: 591-609.

41 Weedon D. The spitz nevus. Clin Oncol 1984;3:493-507.

42 Echevararria R, Ackerman LV. Spindle and epithelioid cell nevi in the adult. Cancer 1967;20:175-88.

43 Paniago-Periera C, Maize JC, Ackerman AB. Nevus of large spindle and/or epithelioid cells (Spitz's nevus). Arch Dermatol 1978;114:1811-23.

44 Peters MS, Goellner JR. Spitz naevi and malignant melanomas of childhood and adolescence. Histopathology 1986;10: 1289-302.

45 Crotty KA. Spitz naevi. Histological features and distinction from malignant melanoma. Australas f Dermatol 1997;38: 549-53.

46 Peipkorn $M$. On the nature of histologic observations: the case of the Spitz nevus. F Am Acad Dermatol 1995;32:24854.

47 Farmer ER, Gonin R, Hanna MP. Discordance in the histopathologic diagnosis of melanoma and melanocytic nevi between experts. Hum Pathol 1996;27:528-31.

48 Okun MR. Histological demarcation of lateral borders: an unsupportable criterion for distinguishing malignant melanoma from Spitz and compound naevus. Histopathology 1998;33:158-62.

49 Walsh N, Crotty K, Palmer A, et al. Spitz nevus versus spitzoid malignant melanoma. An evaluation of the current distinguishing histopathologic criteria. Hum Pathol 1998; 29:1105-12.

50 Smith KJ, Barrett TL, Skelton HG, et al. Spindle and epithelioid cell nevi with atypia and metastasis (malignant Spitz nevus). Am f Surg Pathol 1989;13:931-9.

51 Busam KJ, Barnhill RL. The spectrum of Spitz tumours. In: Kirkham N, Lemoine NR, eds. Progress in pathology, Vol. 2. Edinburgh: Churchill Livingstone, 1995:31-46.

52 Barnhill RL, Flotte TJ, Fleischli M, et al. Cutaneous melanoma and atypical Spitz tumours in childhood. Cancer 1995;76:1833-45.

53 Smith NM, Evans MJ, Pearce A, et al. Cytogenetics of an atypical Spitz nevus metastatic to a single lymph node. Pediatr Pathol Lab Med 1998;18:1115-22.

54 Seab JA, Graham JH, Helwig EB. Deep penetrating naevus. Am $\mathcal{F}$ Surg Pathol 1989;13:39-44.

55 Cooper PH. Deep penetrating naevus. A frequent participant in combined naevus. F Cutan Pathol 1992;19:172-80.

56 Mehregan DA, Mehregan AH. Deep penetrating naevus. Arch Dermatol Res 1993;129:328-731.

57 Mehregan DR, Mehregan DA, Mehregan AH. Proliferating cell nuclear antigen staining in deep penetrating naevi. $\mathscr{f}$ cell nuclear antigen staining in deep
Am Acad Dermatol 1995;33:685-7.

58 Barnhill RL, Mihm MC, Magro CM. Plexiform spindle cell naevus: a distinctive variant of plexiform melanocytic naevus. Histopathology 1991;18:243-7. 59 Barr RJ, Morales RV, Graham JH. Desmoplastic naevus: a
distinct histological variant of mixed spindle cell and epithelioid cell naevus. Cancer 1980;46:557-64

60 MacKie RM, Doherty VR. The desmoplastic melanocytic naevus: a distinct histological entity. Histopathology 1992; 20:207-11

61 Collina G, Deen S, Cliff S, et al. Atypical dermal nodules in benign melanocytic naevi. Histopathology 1997;31:97-101.

62 Ball NJ, Golitz LE. Melanocytic naevi with focal atypical epithelioid cell components: a review of seventy three cases. f Am Acad Dermatol 1994;30:724-9. 
63 Reed RJ, Ichinose H, Clark WH, et al. Common and uncommon melanocytic naevi and borderline melanomas. uncommon melanocytic nae

$64 \mathrm{McG}$ overn VJ. Sources of difficulty in diagnosis of benign lesions. In: Melanoma histological diagnosis and prognosis. New York: Raven Press, 1983:91-2.

65 Clark WH, Mastrangelo MJ, Ainsworth AM, et al. Current concepts of the biology of human cutaneous melanoma. Adv Cancer Res 1977;24:267-338.

66 Elder DE, Murphy GF. Melanocytic tumours of the skin. Benign melanocytic tumours (naevi), atlas of tumour pathology, 3rd series. Washington DC: AFIP, 1991.

67 Blessing K. Benign atypical naevi: diagnostic difficulties and continued controversy. Histopathology 1999;34:189-98.

67a Kua HW, Blessing K. Benign melanocytic naevi from special anatomic sites [abstract]. F Pathol 1999;189:26A

68 Kao GF, Helwig EB, Graham JH. Balloon cell malignant melanoma of the skin: a clinicopathological study of 34 cases with histochemical, immunohistochemical and ulcases with histochemical, immunohistochemical and

69 Conley J, Latterly R, Orr W. Neurotropic malignant melanoma (a rare variant of spindle cell melanoma). Cancer melanoma (a rare

70 Reed JG, Leonard DD. Neurotropic melanoma: a variant of desmoplastic melanoma. Am f Surg Pathol 1979;3:301-11.

71 Bruijn JA, Mihm MC, Barnhill RL. Desmoplastic melanoma. Histopathology 1992;20:197-205.

72 Skelton HG, Smith KJ, Laskin WB, et al. Desmoplastic malignant melanoma. $\mathcal{F}$ Am Acad Dermatol 1995;32:71725.

73 Blessing K, McLaren KM. Histological regression in primary cutaneous melanoma: recognition, prevalence and significance. Histopathology 1992;20:315-22.

74 House NS, Fedock F, Maloney M, et al. Malignant melanoma with the clinical and histologic features of Mer-

75 Nakleh RE, Wick MR, Rocamora A, et al. Morphological diversity in malignant melanoma. Am $\mathcal{f}$ Clin Pathol diversity in malig

76 Kossard S, Wilkinson B. Nucleolar organiser regions and image analysis nuclear morphometry of small cell (nevoid) image analysis nuclear morphometry of small

76a Blessing K, Grant JJK, Sanders DSA, et al. Small cell malignant melanoma: a distinct histopathological entity [abstract]. F Pathol 1999;187:40A.

77 Okun M. Melanoma resembling spindle and epithelioid cell nevus. Arch Dermatol 1979;115:1416-20.
78 Cochran AJ, Bailly C, Paul E, et al. Melanocytic tumors: a guide to diagnosis. New York: Lippincott-Raven, 1997.

79 Casso EM, Grin-Jorgensen CM, Gant-Kels JM. Spitz nevi. f Am Acad Dermatol 1992;27:901-13.

80 Blessing K. Malignant melanoma in stasis dermatitis. Histopathology 1997;30:135-9.

81 Levene A. On the histological diagnosis and prognosis of malignant melanoma. f Clin Pathol 1980;33:101-24.

82 Kuehnl-Petzoldt C, Berger H, Wiebelt H. Verrucouskeratotic variations of malignant melanoma. A clinicopathological study. Am f Dermatopathol 1982;4:403-10.

83 Schmoeckel C, Castro CE, Braun-Falco O. Naevoid malignant melanoma. Arch Dermatol Res 1985;277:362-9.

84 Blessing K, Evans AT, Al-Naffussi A. Verrucous naevoid and keratotic malignant melanoma: a clinico-pathological study of 20 cases. Histopathology 1993;23:453-8.

85 Cochran AJ, Bailly C, Paul E, et al. Naevi, other than dysplastic and Spitz naevi. Semin Diagn Pathol 1993;10:317

86 Wong T, Suster S, Duncan L, et al. Naevoid melanoma: a clinicopathological study of seven cases of malignant melanoma mimicking spindle and epithelioid cell naevus and verrucous dermal naevus. Hum Pathol 1995;26:171-9.

87 McNutt NS. "Triggered trap": naevoid malignant McNutt NS. "Triggered trap": naevoid
melanoma. Semin Diagn Pathol 1998;15:203-9.

88 Phillips ME, Margolis RJ, Merot Y, et al. The spectrum of minimal deviation melanoma: a clinicopathologic study of 21 cases. Hum Pathol 1986;17:796-806.

89 Reed RJ, Martin P. Variants of melanoma. Semin Cutan Med Surg 1997;16:137-58.

90 Heenan PJ, Clay CD. Epidermotrophic metastatic melanoma simulating multiple primary melanomas. $A m$ f Dermatopathol 1991;13:396-402.

91 Mehregan DA, Bergeon MT, Mehregan DR. Epidermotrophic metastatic malignant melanoma. Cutis 1995;55: 225-7.

92 Kossard S, MacKenzie-Wood A. Dysplastic junctional nevus of the elderly or naevoid lentigo maligna [abstract]. Am f Dermatopathol 1999;21:72a.

$93 \mathrm{Kempf}$ W, Haeffner AC, Mueller B, et al. Experts and gold standards in dermatopathology. Am $\mathcal{F}$ Dermatopathol 1998; 20:478-82.

94 Harmse JL, Evans AT. Proliferation and apoptotic indices in Spitz lesions [abstract]. F Pathol 1999;189:26A. 